\title{
Exploration on the International Development of Event Major Based on the Construction of International Conference Site
}

\author{
Jiankang Zhang, a \\ ${ }^{1}$ School of International Economy \& Tourism Management, Zhejiang International Studies University, Hangzhou, \\ Zhejiang 310023, China \\ ahangjk@zisu.edu.cn
}

\begin{abstract}
Event major in universities of Zhejiang needs to target at the construction of Hangzhou international conference site, and achieves international development in teachers, teaching contents and methods, teaching media and technology, audiences, teaching effect and other overall elements. The concrete measures include: Establish training objectives and specifications matching international conference site; Design international conference curriculum systems based on National Standard; Build a talent cultivating mechanism with the cooperation of "government-association-enterprise-university"; Build "full-time teachers and industry executives" teams; Establish international conference training bases and innovation and entrepreneurship bases; Promote international teacher-student exchanges and overseas internship programs, etc. Keywords: international conference site, event major, international development
\end{abstract}

\section{基于国际会议目的地建设的会展专业国际化发展探索}

\author{
张健康 ${ }^{1,}$ a \\ ${ }^{1}$ 浙江外国语学院国际经济与旅游管理学院, 杭州, 浙江, 310023, 中国 \\ ahangjk@zisu.edu.cn
}

中文摘要.

浙江省高校会展专业需要对接杭州国际会议目的地建设目标，在教师、教学内容和方法、教学媒介和 科技、受众、教学效果等全要素上推进国际化发展。具体举措包括: 确立与国际会议目的地匹配的培 养目标和规格；在《国标》基础上设计国际会议课程体系；建设 “政府-协会-企业-高校” 四方协同的 人才培养机制；打造 “专任教师+行业高管” 的双师团队; 创办国际会议实训基地和创新创业基地; 推 进国际师生交流和海外实习项目等。

关键词：国际会议目的地；会展专业；国际化发展

\section{1. 引言}

浙江省杭州市政府在《杭州市会展业发展 “十三五” 规划》提出 “努力建设全球知名的国际会议目的地” , 随后在《杭州市加快推进会展业发展三年行动计划 （2018-2020年）》, 又强调要 “加快推进国际会议 目的地建设, 打响 “峰会杭州” 品牌, 提升 “要开会到 杭州” 的知名度”。而在 2016 年杭州G20峰会以后, 杭 州会议业得到快速发展。根据国际大会与会议协会 (ICCA) 最新发布的2018年度全球会议目的地城市排行 榜, 2018年中国大陆会议强市分别为北京、上海、杭
州、西安、广州成功跻身全球 100 强, 杭州紧随北京、 上海, 位于第三。

国际会议目的地离不开人才的支撑, 同时国际会议 目的地的建设也将大大增加会展人才需求。杭州市政府 在推进会展业发展过程中, 一直高度重视会展业人才培 养, 提出打造 “最具影响力的中国会展人才培养基地” 。 而如何把握国际会议目的地建设契机，加快会展专业国 际化发展, 是浙江省高校会展专业需要思考的问题。 
会展策划与管理。在落实《国标》的基础上, 会展专业 要厘清杭州市国际会议目的地建设需要人才的知识、素 质和能力结构, 设置 2 个课程模块: 国际会议类课程模 块和目的地管理类课程模块。

国际会议类课程模块包括: 国际会议策划与文案国 际会议项目管理、国际会议商务服务、国际会议接待礼 仪、国际会议沟通技巧、国际会议英语、国际会议场地 运营、会议设施操作与管理等8门课程。

目的地管理类课程模块包括: 城市学概论、城市经 济学、城市品牌传播、国际会议目的地概论、会议目的 地市场营销、会议目的地品牌管理等6门课程。

\begin{tabular}{|c|c|c|c|c|}
\hline Who & $\begin{array}{c}\text { Says } \\
\text { what }\end{array}$ & $\begin{array}{c}\text { In which } \\
\text { channe1 }\end{array}$ & To whom & $\begin{array}{c}\text { With what } \\
\text { effect }\end{array}$ \\
\hline 谁 & 说什么 & $\begin{array}{c}\text { 通过什么 } \\
\text { 渠道 }\end{array}$ & 给谁 & $\begin{array}{c}\text { 取得什么 } \\
\text { 效果 }\end{array}$ \\
\hline 传播者 & 讯息 & 媒介 & 受众 & 效果 \\
\hline
\end{tabular}

\section{3. 会展专业国际化发展的具体举措}

专业建设的基本逻辑确立培养目标和规格、课程体 系、培养机制、师资队伍、培养条件等, 并结合会展专 业国际化发展模型的五要素, 推进实施基于国际会议目 的地建设的会展专业国际化发展的具体举措。

\section{1 确立与国际会议目的地匹配的培养目标和 规格}

高校应该按照国际会议目的地建设的目标, 本着培 养 “复合型、涉外型、应用型” 人才的理念, 确立了 “以 外语交际能力为特色, 以国际化应用型为导向, 以全球 发展为目标” 确立人才培养目标和规格, 确立独具特色 的专业与外语相复合的会展专业人才培养模式。外国语 院校还可以结合自身的外语办学优势, 开设 “专业+外 语” 的专业方向, 如 “国际会议英语”、“国际会议西 班牙语”、“国际会议德语” 等, 培养既懂得国际会议 管理, 又有外语特长的国际会议人才。随着世界旅游联 盟总部、丝绸之路国际联盟总部相继落户杭州, 相关高 校在人才培养目标和规格上也需要呼应和对标这些组 织对会议人才的需要。另外, 会展专业应该开展国际会 展人才培养质量认证, 使得人才培养目标和规格达到国 际认可标准, 以更好适应国际会议目的地建设的需要。

\section{2在《国标》基础上设计国际会议课程体系}

首先是落实《旅游管理类教学质量国家标准》。该 《国标》旨在提高本科教学质量和水平, 促进高等教育 服务于国家与地方经济社会的发展需要, 是旅游管理类 本科专业建设的基本要求。该《国标》提出了旅游管理 类本科专业的 “ $4+3$ ” 课程建设标准。 “ 4 ” 指的是 4 门 大类核心课程, 包括旅游学概论、旅游接待业、旅游目 的地管理、旅游消费者行为, “ 3 ” 指的是 3 门专业核 心课程, 具体到会展专业, 则是会展概论、会展营销、

\section{3建设 “政府-协会一企业-高校” 四方机制}

培养人才不仅是高校的使命，也是政府、协会确保 建设实现的重要保障; 而企业作为用人单位, 人才是企 业的第一生产力, 理应将人才培养和使用做一体化管 理。政府职能部门要以国际会议目的地建设为由头, 牵 头构建 “政府-协会-企业-高校” 四方协同的人才培养 机制, 并制定政策支持和鼓励举措, 引导和扶持协会、 企业、高校协同培养会展人才。行业协会作为沟通者和 组织者, 可以很好地发挥政府、企业、高校的桥梁和中 介作用, 有效反馈企业用人需求, 为高校整合行业资源, 推进会展人才培养。浙江省国际会展业协会与浙江外国 语学院关系紧密, 在全国率先共同举办省级 $\mathrm{A}$ 类大学生 会展策划创意大赛, 获得热烈反响。企业拥有国际会议 项目资源和资深从业者, 这些都是高校会展人才培养的 重要资源; 而国际会议项目运作中所需的大量临聘人 员, 也恰好可以为会展专业学生行业实践和考察的机 会。高校作为人才培养主体, 需积极对接政府、协会、 企业的资源，设置柔性教学安排机制对接项目运作时间 上的刚性, 把国际会议项目资源转化为教学资源, 创新 开展会议类人才的培养。为了更好地提升国际会议类人 才的培养水平, 高校应该做好两件工作：一是在开设本 专科学历层次基础上, 争取开设会议类硕士、博士研究 生教育层次, 提升国际会议人才的培养的深度; 二是加 快提升会议相关学科建设, 加强国际会议目的地相关的 学术支撑, 增加会议人才的培养厚度。借助 “政府一协 会-企业-高校” 四方协同的人才培养机制, 相关各方可 以进一步建立会展职业培训机制, 积极开展多层次国际 会议职业教育和从业人员在职培训; 组织业内专家、学 者和项目主办方等开展会展人沙龙、“会议管家培训 班”、“策展人精英培训班”、国际化会展战略人才以 及高层次国际化会展战略人才培训等项目, 为国际会议 目的地建设培育行业精英 $[1]$ 。

\section{4打造 “专任教师+行业高管” 的双师团队}

在会展专任师资方面, 首先是一个数量问题。《国 标》在专业开设标准上提出了 “专任教师数量不少于 10 人” 的要求。根据了解, 国内不少高校会展专业在师资 
台湾静宜大学、澳大利亚格里菲斯大学、日本平安女子 学院等。通过与这些大学的旅游学科之间开展教师短期 授课、交换生、海外实习、留学生实习等项目为会议人 才的国际化培养提供了坚实平台, 提升了师生的国际化 发展能力和水平。浙江外国语学院实现了海外留学生与 中国学生同班上课, 增加了课堂的多元化和国际化。在 海外实习项目方面, 高校可以通过海外合作高校, 也可 以参考目前社会商务公司海外实习项目业务模式，成立 专门的机构来为专门负责这块工作, 为会展及相关专业 学生联系海外高星级酒店实习, 大幅提升师生通过实习 项目的国际化输出规模, 培养师生适应国际工作和生活 环境的能力 $[4]$ 。

\section{4. 结语}

浙江省地方高校会展专业应该以服务地方经济社 会发展为已任, 主动服务于浙江开放强省和城市国际 化, 积极对接杭州市国际会议目的地建设的人才需求, 推进自身的国际化发展, 培养出高质量会展人才。

\section{致谢}

高校应该为会展专业提供必要的空间和场所，来创 办校内的国际会议实训基地和创新创业基地。其实各个 高校都有会议室、招待所和酒店, 都可以成为国际会议 人才的国际会议实训基地和创新创业基地。在这方面, 会展专业师生应该积极争取, 而学校领导应该开明开 放, 敢于放手, 让师生在这些空间里锻炼和展现专业能 力 [3]。在校外基地的建设方面, 杭州市政府在《三年 行动计划》中提出: “依托现有会展场馆以及各类文化 创意园区, 社会化运作场馆, 打造会展创新创业基地, 为会展企业孵化、项目培育和人才培养服务”。高校应 该利用好相关政策, 挖掘和利用相关会展设施资源, 开 展主题化实习活动, 构建理论和实践循环互动机制, 加 强人才的实践应用性。杭州市发展会展业服务中心大力 推进院校、科研机构、职业培训机构与会展企业合作建 立会展产业教学、科研和培训基地, 聘请专家学者为基 地专职或兼职教授, 为会展国际化人才的培养工作做了 大量工作。浙江外国语学院会展专业在省内主要会展公 司和机构都设置了教学实践基地。建立在这些基地基础 上, 浙江外国语学院的学生的专业应用能力得到较好的 培养, 学生在参与省内和全国会展策划比赛中, 屡获殊 荣, 得到业界肯定。

\section{6推进国际师生交流和海外实习项目}

高校应该积极联系国际会展院校, 开展国际师生交 流和海外实习项目, 培育具有国际化视野的会展业高级 应用型人才。在国际师生交流方面, 浙江外国语学院会 展专业依托学校与国外多所大学建立了稳固的合作关 系, 主要有西班牙萨拉曼卡大学、墨西哥科利马大学、
本文为2018年浙江省教育科学规划研究 课题《基于国际会议目的地建设的会展专业国 际化特色发展研究》研究成果之一。浙江外国 语学院-浙江省 “十三五” 优势专业旅游管理 专业建设项目成果。

\section{REFERENCES}

[1] B.Huang, Discussion on How to Build "International Conference Site"in Hangzhou, Journal of Urumchi Vocational University, vol.1, pp.63-67, 2015.

[2] T.M.Shen, A Brief Discussion on International Perspectives of Exhibition Talent Cultivation, Journal of Chifeng University (Natural Science Edition), vol.10, pp.46-48, 2009.

[3] R.Qian, A Brief Analysis of the Development Opportunities Brought by "The Belt and Road" Strategy to Foreign Language Colleges and Universities-Thoughts on International Event Major Talents Training,vol.3, pp.27-30,2017.

[4] N.Jin and X.Z.Shi, Construction of a Hierarchical and Reciprocal Practical Teaching System for Event Major Based on School and Enterprise Cooperation, Journal of Kaifeng College of Education, vol.12, pp.144-145,2019. 